\title{
Biomass burning emission inventory from burnt area data given by the SPOT-VEGETATION system in the frame of TRACE-P and ACE-Asia campaigns
}

\author{
C. Michel, ${ }^{1}$ C. Liousse, ${ }^{1}$ J.-M. Grégoire, ${ }^{2}$ K. Tansey, ${ }^{3}$ G. R. Carmichael, ${ }^{4}$ and J.-H. Woo ${ }^{4}$
}

Received 23 September 2004; revised 11 January 2005; accepted 27 January 2005; published 3 May 2005.

[1] One of the main uncertainties in the estimation of the climatic impact of aerosols is linked to our knowledge of gas and aerosol emissions. This is particularly crucial over Asia, where a strong regional fingerprint is observed, with different emission types, depending on the various vegetation and climate conditions (biomass burning emissions) and on the very fast changes of the population and industrialization (biofuel and fossil fuel emissions). The main contribution of this work is to derive a biomass burning inventory of $1^{\circ} \times 1^{\circ}$ over Asia (the Asian biomass burning inventory (ABBI)) for gases and particles for the Aerosol Characterization Experiment-Asia (ACE-Asia) and Transport and Chemical Evolution Over the Pacific (TRACE-P) campaign period (March to May 2001) in 2001. In this paper we apply. new estimates of burnt biomass area to estimate emissions. The method is based on burnt areas (GBA2000 project; Tansey et al. (2002) and Grégoire et al. (2003)) obtained from $1 \mathrm{~km}$ resolution SPOT-VEGETATION satellite data. Regional-scale maps of burnt areas are produced, and then spatial and temporal emission distribution are obtained from biomass density and emission factors. Strength and weaknesses associated with the use of satellite products are discussed, including the problem of subpixel classification and the lack of validation data for the accuracy assessment of the products for the studied area. Estimated emissions are compared with ACE-Asia and TRACE-P Modeling and Emission Support System (ACESS) climatological estimates. In addition, interannual variability is estimated by preparing inventories for the years 2000 and 2001.

Citation: Michel, C., C. Liousse, J.-M. Grégoire, K. Tansey, G. R. Carmichael, and J.-H. Woo (2005), Biomass burning emission inventory from burnt area data given by the SPOT-VEGETATION system in the frame of TRACE-P and ACE-Asia campaigns, J. Geophys. Res., 110, D09304, doi:10.1029/2004JD005461.

\section{Introduction}

[2] Emissions from biomass burning are known to significantly contribute to the injection of gases and aerosols in the atmosphere with local and global impacts. There is a huge uncertainty in biomass buming emission inventories, used for modeling exercises. The existing inventories (EDGAR [Olivier and Berdowski, 2001] and GEIA (http://weather.engin.umich.edu/geia/index.html)) [see also Cooke and Wilson, 1996; Liousse et al., 1996; Streets et al.,

\footnotetext{
'Laboratoire d'Aérologie, Observatoire Midi-Pyrénées, Unité Mixte de Recherche 5560, Centre National de la Recherche Scientifique, Université Paul Sabatier, Toulouse, France.

${ }^{2}$ European Commission's Joint Research Centre, Institute for Environment and Sustainability, Ispra, Italy.

${ }^{3}$ Department of Geography, University of Leicester, Leicester, UK.

${ }^{4}$ Center for Global and Regional Environmental Research, University of Iowa, Iowa City, Iowa, USA.
}

Copyright 2005 by the American Geophysical Union. 0148-0227/05/2004JD005461\$09.00
2003] are based on the relationship between the burnt biomass and the emission flux, linked by emission factors dependent on the combustion type and consequently on the burnt vegetation type [Seiler and Crutzen, 1980]. During the last decade, the characterization of the emissions has significantly improved. A series of experiments in Africa (DECAFE 1988, 1991, see http://www.insu.cnrsdir.fr/documentation/Insu_doc/decafe_cadre_gene.html, SAFARI 1992, 2000, see http://safari.gecp.virginia.edu/ abstract/index.asp, EXPRESSO, see http://www.insu.cnrsdir.fr/documentation/Insu_doc/expresso.html) and in the United States and Brazil (SCAR C, SCAR B, see http:// asd-www.larc.nasa.gov/scar/) have allowed the determination of emission factors for many chemical species, as a function of the combustion mode, with good accuracy [Andreae and Merlet, 2001; Liousse et al., 2004]. Large uncertainty remains in the estimate of bumt biomass and in the temporal dynamics, namely seasonal and interannual, of this variable, and therefore on the assessment of burning efficiency and fire intensity. Most of the inventories quoted previously were based on the determination of the mean burnt biomass obtained from statistical data or for a climatic 


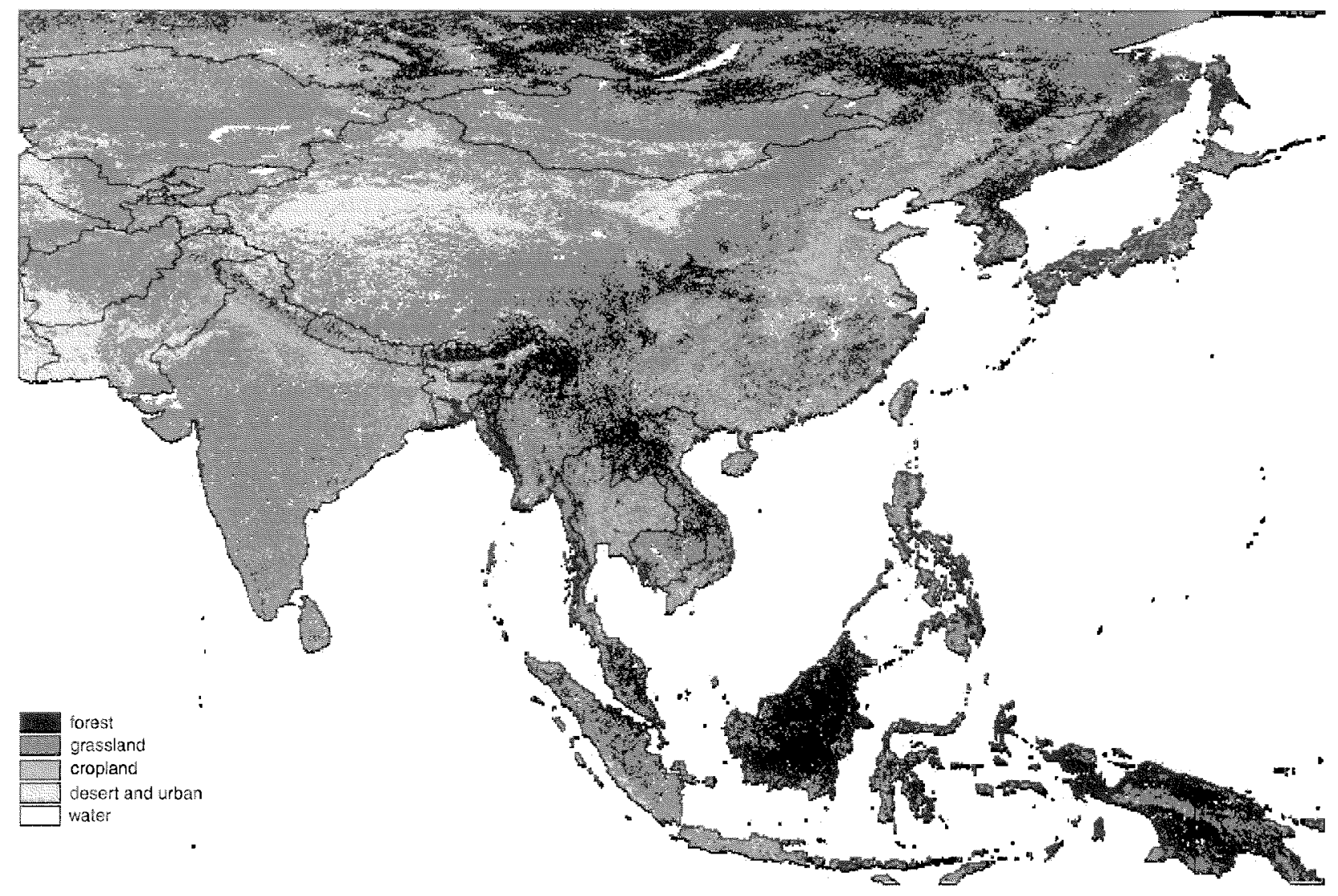

Figure 1. A land cover map [Hansen et al, 2000] of the study area: $10^{\circ} \mathrm{S}-60^{\circ} \mathrm{N} ; 59^{\circ} \mathrm{E}-150^{\circ} \mathrm{E}$.

year. For example, Hao et al. [1990] and Cooke and Wilson [1996] assumed that about $80 \%$ of the savanna is burned in Africa on an antual basis.

[3] Recent developments centered on Africa have put forward a new method based on satellite imagery in order to better take into account spatial and temporal emission distributions. Satellite imagery provides both a long time series a high spatial frequency of fire products [Cooke et al., 1999; Barbosa et al., 1999; Liousse et al., 2004]. At the global scale, a new product from the European Space Agency (ESA) based on burnt area data [Hoelzemann et al., 2004] has been released. Some of these studies have chosen to use the burnt area instead of "hot spots" (active fire occurrences) products. Indeed, as mentioned in the work of Liousse et al. [2004], only a qualitative improvement could be possible with fire pixel products. The use of burnt area products allows us to minimize the effect of temporal sampling, i.e., the burnt areas have a spectral signature that can be observed over a longer time period and consequently this results in a quantitative improvement in the assessment of the burnt biomass.

[4] This paper presents a new emission inventory for biomass burning: Asian Biomasss Burning Inventory (ABBI) for a large region of Asia based on the use of burnt area products for 2000 and 2001. Emissions are derived for a suite of gaseous compounds and aerosols. In the first part of the paper the methods used to derive the burnt areas and emissions from satellite data are described. Results of this analysis are presented in the second part. These estimated emissions are compared to those based on fire counts and burnt areas developed for ACE-Asia and TRACE-P Modeling and Emission Support System (ACESS) by Streets et al. [2003] and Woo et al. [2003]. Finally, the ABBI estimates are compared for years 2000 and 2001 .

\section{Method}

[5] In this section, the procedure for deriving gas and particle emissions from satellite data is described including a presentation of the satellite data, a description of methods used to estimate burnt areas and then to derive emissions. The study area, presented in Figure 1, extends from the west of Kazakhstan (Ural Mountains) to the cast of Japan and from the center of Russia to the south of Indonesia $\left(10^{\circ} \mathrm{S}-\right.$ $60^{\circ} \mathrm{N}, 59^{\circ} \mathrm{E}-150^{\circ} \mathrm{E}$ ). Indeed, such a frame allows us to take inlo account the fires expected to have the greatest impact on the ACE-Asia [Huebert et al., 2003] and TRACE-P (http://code916.gsfc.nasa.gov/Missions/TRACEP/) experiment zones.

\subsection{Data Sources}

[6] SPOT-VEGETATION imagery [Eastwood et al., 1998; Fraser and $L i, 2002]$ was used to produce the burnt area maps during the ACE-ASIA and TRACE-P campaigns 
Table 1. Emission Factors for the Different Vegetation Classes of the UMD Product

\begin{tabular}{lc}
\hline \multicolumn{1}{c}{ Vegetation Class } & Corresponding EF \\
\hline Evergreen needleleaf forest & extratropical forest \\
Evergreen broadleaf forest & tropical forest \\
Deciduous needleleaf forest & extratropical forest \\
Deciduous broadleaf forest & extratropical forcst \\
Mixed forest & extratropical forest \\
Woodland & grassland \\
Wooded grassland & mean (extratropical + grassland) \\
Closed shrubland & grassland \\
Open shrubland & grassland \\
Grassland & cropland \\
Cropland &
\end{tabular}

from March to May 2001 and from March to May 2000. The VEGETATION sensor on board the SPOT-4 platform was launched in March 1998 (http://spot-vegetation.com). The instrument observes a region of the Earth $2250 \mathrm{~km}$ wide with daily coverage. The satellite has an equatorial local crossing time of 10:30 in the moming local solar time. The across track resolution is approximately $1.1 \mathrm{~km}$ at nadir. The data are projected and interpolated to a constant pixel resolution of approximately $1 \mathrm{~km}^{2}$. Four spectral bands are available: B0 between 0.43 and $0.47 \mu \mathrm{m}$ (blue), B2 between 0.61 and $0.68 \mu \mathrm{m}$ (red), B3 between 0.78 and $0.89 \mu \mathrm{m}$ (near infrared) and SWIR between 1.58 and $1.75 \mu \mathrm{m}$ (SWIR). The SWIR band, centered on $1.65 \mu \mathrm{m}$, has been proved to be useful for mapping burnt areas [Eastwood et al., 1998; Eva and Lambin, 1998; Trigg and Flasse, 2000]. Daily surface reflectance (S1) products were used for this study. The information on the land cover type, also required to compute the emissions, was derived from the University of Maryland (UMD) global land cover product [DeFries et al., 1998; Hansen et al., 2000]. This land cover map includes 11 classes of vegetation that are listed in the Table 1.

\subsection{Deriving Burnt Area Maps From SPOT-VEGETATION S1 Imagery}

[7] The processing chain, developed for the Global Burnt Area 2000 (GBA2000) project [Grégoire et al., 2003; Tansey et al., 2004] was applied to the S1 images that were obtained for the period of interest: March to May 2001. Burnt areas for March to May 2000 were already available from the GBA2000 product.

\subsubsection{Preprocessing of the SPOT-VEGETATION} Imagery

[8] Before we apply the algorithm developed to yield burnt areas, the satellite data need to be effectively filtered. The quality of the results highly depends on this process. Briefly, this image preprocessing module can be separated into two parts. The first procedure removes pixels that could be detected as bumt pixels but which are not bumt, and include cloud shadows, water bodies and nonvegetated surfaces, or pixels with extreme values that could influence the operation of the algorithm. The second phase involved compositing of cloud and cloud shadow free daily images to produce a reference image to which the burnt area algorithm was applied.

\subsubsection{Processing Module: Burnt Area Algorithm}

[9] The algorithm, developed for GBA2000 by Ershov and Novik [2001] of the International Forestry Institute (IFI) of Russia was used. This algorithm examines spectral characteristics on subregions of 200 by $200 \mathrm{~km}$ and derives burnt areas using two different methods depending on whether the land cover is forested or not.

\subsubsection{Postprocessing Module}

[10] In order to remove possible large remaining errors in the burnt area results, a postprocessing module is applied. It consists of the removal of a one pixel expanded water mask in order to remove problems occurring at shorelines [Tansey, 2002].

\subsubsection{Output Products: Uncertainties and Quality} Assessment

[11] The output products are the location (in latitude and longitude) of the pixels classified as burnt and the date of burning (http://www.gvm.jrc.it/fire/gba2000/index.htm). However, large uncertainties remain. These have recently been discussed in the work of Tansey et al. [2004, 2005]. A quantitative accuracy assessment of the overall GBA2000 products is ongoing [Boschetti et al., 2004a, 2004b, 2004c]. For what concerns the uncertainty in the determination of the area effectively burned, previous work by Eva and Lambin [1998] has shown that a $1 \mathrm{~km}^{2}$ pixel is classified as burnt when at least $50 \%$ ( 50 hectares (ha) in this case) of the area covered by the pixel is effectively bumt. This introduces an uncertainty when translating the number of pixels classified as burnt into an area. It also introduces a spatial filter, with burnt areas less than 50 hectares in size likely not detected. Another uncertainty is linked to the quantity of biomass actually bumt within each pixel. The burning efficiency varies widely as a function of the vegetation type and of the meteorological conditions at the time of the fire.

[12] The second group of uncertainties is linked to a series of difficulties encountered during data processing, especially due to the regional conditions and the timing of the study. For example, during the study period there was frequent dense cloud cover, small and scattered fires, and a wide range of vegetation cover types (desert to evergreen moist forest) and frequent precipitation due to the monsoon season commenced at the end of the experimental period.

[13] In order to check the consistency of our results, approximately twelve high resolution satellite imagery (Landsat TM $30 \mathrm{~m}$ resolution quick looks 2001) was analyzed over some areas where problems were observed. The comparison was satisfactory because the burnt scars observed in TM high resolution images were visible in the SPOT-VEGETATION low resolution data, despite the different spatial resolution.

\subsection{Determination of the Emission Inventory}

\subsubsection{Multi-Information Map Preparation}

[14] The burnt area maps, resulting from the above procedure were combined with other sources of data including vegetation maps, administrative maps and $1^{\circ} \times 1^{\circ}$ grid maps. The data sets were entered into a Geographic Information System (GIS) to provide products of different categories such as burnt areas crossed with country and vegetation type, and burnt areas crossed with country and $1^{\circ} \times 1^{\circ}$ grids. Furthermore, the burnt area maps at a resolution of $1 \mathrm{~km}^{2}$ were crossed with the UMD land cover map, also at a resolution of $1 \mathrm{~km}^{2}$. These categorized products provide information on the vegetation type that has been burnt in each $1^{\circ} \times 1^{\circ}$ grid square during the time 
Table 2. Primary Carbonaceous Aerosol Emissions Factors for the Eleven Vegetation Classes of the UMD Land Cover

\begin{tabular}{lll}
\hline \multicolumn{1}{c}{ Vegetation Class } & EF(BC) & EF(OC) \\
\hline Evergreen needleleaf forest & 0.6 & 6 \\
Evergreen broadleaf forest & 0.7 & 6.4 \\
Deciduous needleleaf forest & 0.6 & 6 \\
Deciduous broadleaf forest & 0.6 & 6 \\
Mixed forest & 0.6 & 6 \\
Woodland & 0.61 & 5 \\
Wooded grassland & 0.62 & 4 \\
Closed shrubland & 0.61 & 5 \\
Open shrubland & 0.62 & 4 \\
Grassland & 0.62 & 4 \\
Cropland & 0.725 & 2.1 \\
\hline
\end{tabular}

period and over the area of study. These products were then re-sampled to a resolution of one degree. As an example of results of this analysis, we estimate that on 4 May, the fire associated with burnt pixels located at a grid centered at $17.5^{\circ} \mathrm{N}$ and $76.5^{\circ} \mathrm{E}$ (India), burnt $107 \mathrm{~km}^{2}$ of wooded grassland, $6 \mathrm{~km}^{2}$ of closed shrub land, $18 \mathrm{~km}^{2}$ of open shrub land and $8 \mathrm{~km}^{2}$ of grassland (vegetation information was derived from the UMD land cover product). In practice daily burnt area estimates are not used because of the large uncertainty in their accuracy. Concerning the temporal distribution, we expect an error between 5 days (delay between two observations at nadir) and 10 days (time during which a burnt scar remains characteristic) in the detection of the burnt area, especially in cloudy areas (for more information, see section 2.2.4).

\subsubsection{Description of Emission Calculations}

[15] The method used for the emission calculation for the species $\mathrm{x}$ is based on the following equation given by Seiler and Crutzen [1980]:

$$
Q(x)=M \times E F(x),
$$

where $Q(x)$ denotes the gas or acrosol emission flux, $M$ the amount of burnt biomass and $\mathrm{EF}(\mathrm{x})$ the emission factor given for the species $\mathrm{x}$ in grams of $\mathrm{x}$ per kilogram of dry matter $(\mathrm{gx} / \mathrm{kgdm})$.

[16] The emission factors given by Andreae and Merlet [2001] were used for the gases. For particles, the emission factors for both black carbon (BC) and primary organic carbon $\left(O C_{p}\right)$ are summarized in Table 2 for each UMD vegetation class. These values have been specially selected for Asia study region and for the classes of the UMD land cover map (11 vegetation classes) present in the area, including recent experiments and reviews [Liousse et al., 2004]. In some cases, EF values were not available for a specific vegetation class. Therefore correspondences between the UMD vegetation classes and main vegetation types with well known EF have been assumed from vegetation properties, as shown in Table 1. The particle $\mathrm{EF}$ were selected from results from ground and airplane measurements, which emission factors for $\mathrm{OC}_{\mathrm{p}}$ were taken from ground measurements, and therefore do not include secondary formation of organics.

[17] Values for tropical forest and savanna fires were selected following Liousse et al. [2004]. Values for extratropical forest fires were chosen following Stssott et al. [1991] and Hobbs et al. [1996]. Values for cropland buming were based on Liousse et al. [1996].
[18] The amount of burnt biomass $M$ is given by Seiler and Crutzen [1980]:

$$
M=A \times B \times \alpha \times \beta,
$$

where $A$ is the burnt area $\left(\mathrm{m}^{2}\right), B$ the biomass density $\left(\mathrm{g} / \mathrm{m}^{2}\right)$, $\alpha$ the fraction of aboveground biomass, and $\beta$ the buming efficiency. The value of $A$ is provided by the satellite techniques described previously.

[19] The estimates of $\alpha$ and $\beta$ are based on recent improvements in vegetation parameterization [Barbosa et al., 1999; Scholes et al., 1996; Van der Werf et al., 2003]. Table 3 provides values of the burning efficiency $\beta$ for each UMD class, based on a review conducted by Palacios et al. [2002], who summarized several studies [Akeredolu and Isichei, 1991; Bilbao and Medina, 1996; Dignon and Penner, 1991; Hoffa et al., 1996; Hurst et al., 1994; Kasischke et al., 2000; Levine, 2000]. Values of the aboveground biomass density $\mathrm{B}^{\prime}(=\mathrm{B} \times \alpha)$ are given in Table 3 . The values that are available for the vegetation described in the Olson Global Ecosystem (OGE), 21 classes [Olson et al., 1985] have been adapted for the UMD land cover product. In addition, correspondences between vegetation denominations were defined. As an example, woodland and wooded grassland in the UMD land cover product correspond to woody savanna and savanna trees in OGE. It is important to preserve the details within the eleven UMD classes, and this allows us to consider important variations in biomass density values. Indeed, as shown in Table 3 , the range of these values is from $1250 \mathrm{~g} / \mathrm{m}^{2}$ for grassland to $36,700 \mathrm{~g} / \mathrm{m}^{2}$ for evergreen needleleaf forest.

\subsubsection{Temporal Distribution}

[20] One of the main goals of this work is to provide emission estimated with a high temporal resolution. However, although the SPOT-VEGETATION system provides spectral measurements every day, it is only every five days that these measurements are provided under exactly the same viewing conditions. The consequence of this is that the radiometric values for a given location on the ground change from day one to day five and then returns to the original value on day six (provided nothing has changed on the land surface). Ultimately, better confidence is obtained by computing a moving average over five days.

2.3.4. Adaptation of the Emission Inventory to the Needs of Model Input

[21] Emission inventories have been derived for 58 gaseous species and for $\mathrm{BC}$ and $\mathrm{OC}$ particles. In addition

Table 3. Biomass Densities and Buming Efficiencies for the Eleven Vegetation Classes of the UMD Land Cover

\begin{tabular}{lcc}
\hline \multicolumn{1}{c}{ Vegetation Class } & Biomass Density, $\mathrm{g} / \mathrm{m}^{2}$ & Buming Efficiency \\
\hline Evergreen needleleaf forest & 36,700 & 0.25 \\
Evergreen broadleaf forest & 23,350 & 0.25 \\
Deciduous needleleaf forest & 18,900 & 0.25 \\
Deciduous broadleaf forest & 20,000 & 0.25 \\
Mixed forest & 22,250 & 0.25 \\
Woodland & 10,000 & 0.35 \\
Wooded grassland & 3300 & 0.4 \\
Closed shrubland & 7200 & 0.5 \\
Open shrubland & 1600 & 0.85 \\
Grassland & 1250 & 0.95 \\
Cropland & 5100 & 0.60 \\
\hline
\end{tabular}


Table 4. Lumping of the Gas Species Into RACM and ReLACS Species and Their Corresponding Aggregation Factors

\begin{tabular}{|c|c|c|c|c|c|}
\hline ReLACS Species & & Aggregation Factors & RACM Species & Aggregation Factors & Andreae and Merlet [2001] Species \\
\hline NO & & 1 & NO & 1 & NO \\
\hline $\mathrm{NO}_{2}$ & & 1 & $\mathrm{NO}_{2}$ & i & $\mathrm{NO}_{2}$ \\
\hline $\mathrm{SO}_{2}$ & & 1 & $\mathrm{SO}_{2}$ & I & $\mathrm{SO}_{2}$ \\
\hline $\mathrm{CO}$ & & 1 & $\mathrm{CO}$ & 1 & $\mathrm{Co}$ \\
\hline $\mathrm{CO}_{2}$ & & 1 & $\mathrm{CO}_{2}$ & 1 & $\mathrm{CO}_{2}$ \\
\hline $\mathrm{CH}_{4}$ & & 1 & $\mathrm{CH}_{4}$ & 1 & $\mathrm{CH}_{4}$ \\
\hline $\mathrm{N}_{2}$ & & 1 & $\mathrm{~N}_{2}$ & 1 & $\mathrm{~N}_{2}$ \\
\hline $\mathrm{H}_{2}$ & & 1 & $\mathrm{H}_{2}^{2}$ & 1 & $\mathrm{H}_{2}$ \\
\hline ETH & & 1 & ETH & 1 & ethane \\
\hline ALKA & & 0.77 & HC3 & 0.57 & propane \\
\hline ALKA & & 0.77 & $\mathrm{HC} 3$ & 1.11 & n-butane \\
\hline ALKA & & 0.77 & $\mathrm{HC} 3$ & 1.11 & i-butane \\
\hline ALKA & & 0.77 & $\mathrm{HC} 3$ & 0.41 & acethylene \\
\hline ALKA & & 0.77 & HC3 & 0.49 & methanol \\
\hline ALKA & & 0.77 & $\mathrm{HC} 3$ & 0.49 & methyl acetate \\
\hline ALKA & & 0.77 & $\mathrm{HC} 3$ & 1.37 & ethanol \\
\hline ALKA & & 1.23 & HC5 & 0.97 & n-pentane \\
\hline ALKA & & 1.23 & HC5 & 0.97 & n-hexane \\
\hline ALKA & & 1.23 & $\mathrm{HC} 5$ & 0.97 & iso-hexane \\
\hline ALKA & & 1.23 & HC5 & 1.07 & 1 propanol \\
\hline ALKA & & 1.23 & $\mathrm{HC} 5$ & 1.07 & butanol \\
\hline ALKA & & 1.58 & HC8 & 0.9 .4 & heptane \\
\hline ALKE & & 0.96 & ETE & 1 & Ethane \\
\hline ALKE & & 1.04 & OLT & 1 & propene \\
\hline ALKE & & 1.04 & OLT & 1 & I butene \\
\hline ALKE & & 1.04 & OLT & 1 & I pentene \\
\hline ALKE & & 1.04 & OLT & 1 & 4 methyl 1 pentene \\
\hline ALKE & & 1.04 & OLT & 1 & 1 hexene \\
\hline ALKE & & 1.04 & OLT & 1 & octane \\
\hline ALKE & & 1.04 & OLT & 0.5 & i-butene \\
\hline ALKE & & 1.04 & OLT & 1 & styrene \\
\hline ALKE & & 1.04 & OLI & 1 & trans 2 butene \\
\hline ALKE & & 1.04 & OLI & 1 & cis 2 butene \\
\hline ALKE & & 1.04 & OLI & 1 & cyclopentene \\
\hline ALKE & & 1.04 & OLI & 0.5 & i-butene \\
\hline ALKE & - & 1.04 & DIEN & 1 & butandiene \\
\hline BIO & & 1 & ISO & 1 & isoprene \\
\hline ARO & & 0.87 & TOL & 0.29 & benzene \\
\hline ARO & & 0.87 & TOL & 1 & toluene \\
\hline ARO & & 0.87 & TOL & 1 & ethylbenzene \\
\hline ARO & . & 0.87 & TOL & 1 & styrene \\
\hline ARO & & 1.04 & XYL & 1 & xylene \\
\hline ARO & & 1.04 & CSL & 1 & phenol \\
\hline $\mathrm{HCHO}$ & & 1 & HCHO & 1 & formaldehyde \\
\hline ALD & & 1 & ALD & 1 & propenal \\
\hline ALD & & 1 & ALD & 1 & acetaldehyde \\
\hline ALD & & 1 & ALD & 1 & propanal \\
\hline ALD & & 1 & ALD & 1 & butanal \\
\hline ALD & & 1 & ALD & 1 & hexanal \\
\hline ALD & & 1 & ALD & 1 & furfural \\
\hline ALD & & 1 & ALD & 1 & heptanal \\
\hline ALD & & 1 & ALD & 1 & benzaldehyde \\
\hline KET & & 1 & KET & 0.33 & acetone \\
\hline KET & & 1 & KET & 1.61 & 2 butanone \\
\hline KET & & 1 & KET & 1.61 & heptanone \\
\hline KET & & 1 & KET & 1.61 & 2-3 butandione \\
\hline KET & & 1 & KET & 1.61 & pentanone \\
\hline KET & & 1 & KET & 1.61 & octanone \\
\hline 00 & & & ORAl & 1 & formic acid \\
\hline ORA2 & & 1 & ORA2 & 1 & acetic acid \\
\hline
\end{tabular}

emission inventories were adapted to various chemical codes used in subsequent model analysis. An aggregation of the 58 gaseous species into the RACM species was done following Middleton et al. [1990] and Stockwell et al. [1990, 1997], and an aggregation into ReLACS species was performed following Crassier et al. [2000]. Table 4 summarizes the gaseous species that have been taken into account and their distribution for the different RACM and ReLACS classes.

\section{Results}

[22] Figure 2 presents the geographic distribution of black carbon (BC) ABBI based emissions obtained with 
the method previously described, from 1 March to 10 May 2001. More details dealing with spatial and temporal variation are presented in the third subsection below.

\subsection{Comparison of Our Inventory (ABBI) With ACESS Inventory}

[23] A number of modifications were made to $A B B I$ in order to study any similarity and difference with ACESS inventory, which was used by several groups that analyzed the ACE-Asia and TRACE-P observations. BC emission factors from Andreae and Merlet [2001] were used for this comparison, in both the ABBI as well as ACESS inventories. The ACESS window is smaller than the ABBI window: therefore a common window has been selected for the comparison: $10^{\circ} \mathrm{S}-53^{\circ} \mathrm{N}, 60^{\circ} \mathrm{E}-150^{\circ} \mathrm{E}$.

[24] The ACESS inventory was prepared using burnt biomass amount obtained from National Surveys, considered as representative for a generic year in the interval of the 1990-2000. Biomass emissions were spatially and temporally distributed using remote sensing data (hot spots, instead of burnt area maps): The World Fire Web's $0.5^{\circ}$ fire count data of 2001 (NOAA-AVHRR), and the TOMSAI data were used as additional information sources [Streets et al., 2003; Woo et al., 2003]. In this gridding phase, satellite fire counts were found to vary significantly for the FSU countries and Kazakhstan: this contribution of these countries has been consequently excluded from ACESS inventory.

[25] Figure 2 shows the results of the $B C$ emissions estimated by $A B B I$ and $A C E S S$. The total amount of $B C$ in ACESS and ABBI are 1.83E $+05 \mathrm{t}$ and $2.50 \mathrm{E}+05 \mathrm{t}$, respectively.

[26] However, the spatial distributions are different. At the beginning of the TRACE-P period in the ACESS inventory, the emissions are predominantly in Thailand, whereas. the main emission areas are located in central China in ABBI. In the middle and at the end of the campaign, ABBI shows strong emissions in the northern part of the window. These regions were not included in the ACESS inventory as hot spot data was not available during the experiment. Fires in the FSU and Kazakhstan countries represent $1.39 \mathrm{E}+05 \mathrm{t}$ of $\mathrm{BC}$ in the $\mathrm{ABBI}$ inventory, and this contributes to the estimates of ABBI being larger than these fire ACESS. However, ABBI does not observe the large burning activity in India that is shown in ACESS. Such a difference will be partly explained later. Large differences are also observed in terms of temporal distributions. Figure 3 shows that the ACESS inventory, when compared to $\mathrm{ABBI}$, are higher at the beginning of the campaign. At the end of the campaign, ABBI is greater than ACESS, confirming the difference due to the important contribution of the FSU and Kazakhstan countries.

[27] As mentioned by previous studies, the use of burnt areas secms more appropriate to quantitatively derive biomass burnt emissions, especially because it gives good structural information (i.e., geographical area of burnt scar). One rcason for this is the fact that the fire events detected by the polar orbiting satellite systems such as NOAA-AVHRR correspond to only a small fraction of the fire events (i.e., those active during the very short period of the satellite over pass of the day). This introduces a large sampling bias in these products. The bias is much higher when using fire counts than when using burnt areas, as bumt areas integrate the fire activity over a rather long period of time (at least 10 days). Moreover the duration of fire events can be very short, less than one hour in the tropical belt, which means that it is extremely difficult to translate a fire count into a quantitative assessment of area burnt. The ACESS method which is based on a climatic year, made the efforts to correct for this bias.

[28] However, the hot spot approach is probably more efficient for assessing the fire activity in the dense tropical forest, where burnt surfaces are often hidden by the tree canopy and detectable only via the heat flux of the fire event. However, problems arise for intensive fires which tend to saturate the heat flux sensors. The differences between ACESS and ABBI in Southeast Asia can be explained by such a problem.

[29] Consequently, many explanations exist for the differences observed between ACESS and ABBI. Indeed, in the hot spot methods, emissions can be either overestimated, due to the number of pixels really active, or underestimated, due to the heat flux saturation, and to the temporal sampling (satellite passage). In the burnt area method, fire activity in the dense tropical forest is most probably underestimated. As mentioned in section 2.2.4, uncertainty also exists in the use of burnt area products, especially related to estimate of the pixel fraction that is really burnt. Indeed, a $1 \mathrm{~km}^{2}$ pixel is classified as bumt when at least $40 \%$ to $50 \%$ of the area covered by the pixel is effectively burnt. This type of uncertainty also exists when using the hot spot approach. For example in the humid savanna, a fire front of $50 \mathrm{~m}$ gives the spectral signature of an active fire for $1 \mathrm{~km}^{2}$ pixel [Belward et al., 1993].

[30] For the reasons outlined above, this comparison between inventories clearly shows that ABBI approach seems the most appropriate for episode specific analysis. The lack of fires in ACESS in the north of the studied area results in a significant underestimation of the fire emissions (55\% of the total fires). However, the underestimation of the fires by $\mathrm{ABBI}$ for the dense tropical forest is linked only to $7.5 \%$ of the total Asian vegetation.

Figure 2. A comparison of black carbon (BC) emission locations over a 10 day sampling period (the daily emissions are summed) in 2001. (a) BC (ACESS) 1-10 March 2001. (b) BC (ABBI) 1-10 March 2001. (c) BC (ACESS) 11-20 March 2001. (d) BC (ABBI) 11-20 March 2001. (e) BC (ACESS) 20-31 March 2001. (f) BC (ABBI) 21-31 March 2001. (g) BC (ACESS) 1-10 April 2001. (h) BC (ABBI) 1-10 April 2001. (i) BC (ACESS) 11-20 April 2001. (j) BC (ABBI) 11-20 April 2001. (k) BC (ACESS) 21-30 April 2001. (1) BC (ABBI) 21-30 April 2001. (m) BC (ACESS) 1-10 May 2001. (n) BC (ABBI) 1-10 May 2001. (o) BC emissions (t/pixels). See color version of this figure at back of this issue. 


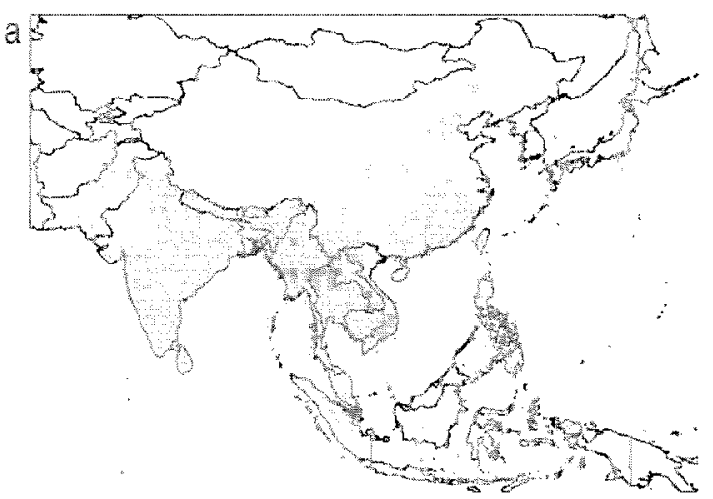

BC (ACESS) 1-10 March 2001

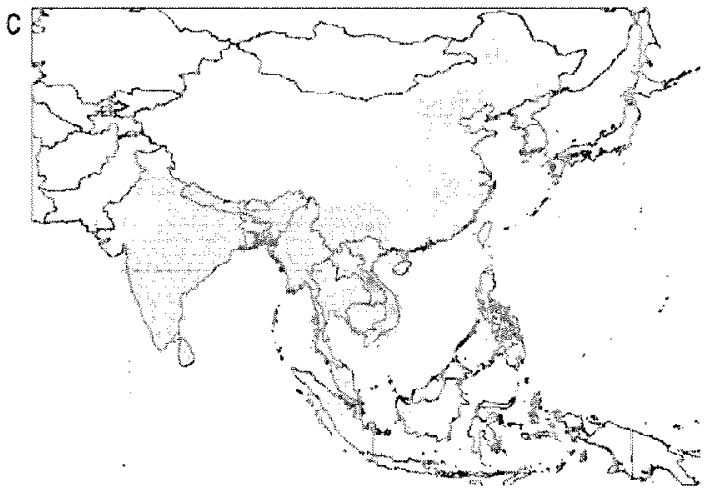

BC (ACESS) 11-20 March 2001

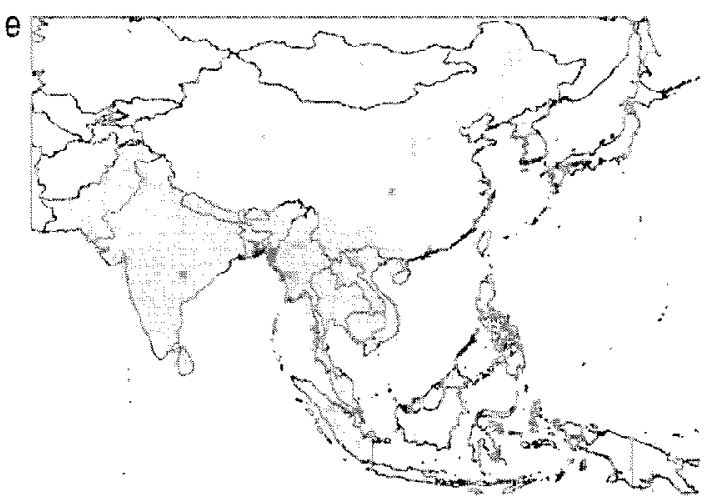

BC (ACESS) 21-31 March 2001

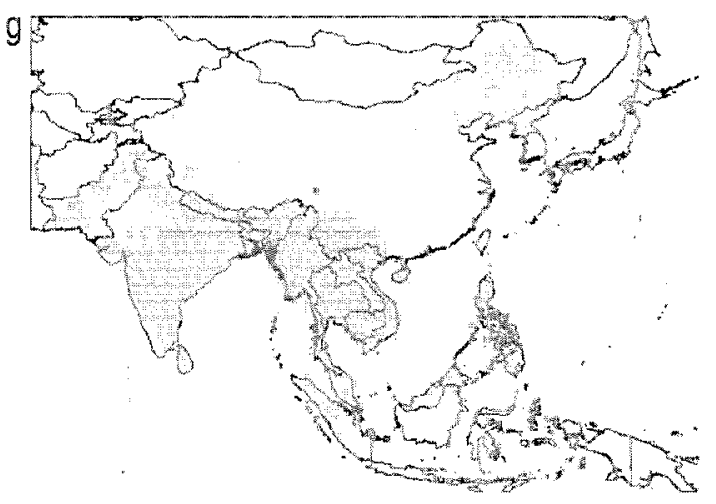

BC (ACESS) 1-10 April 2001

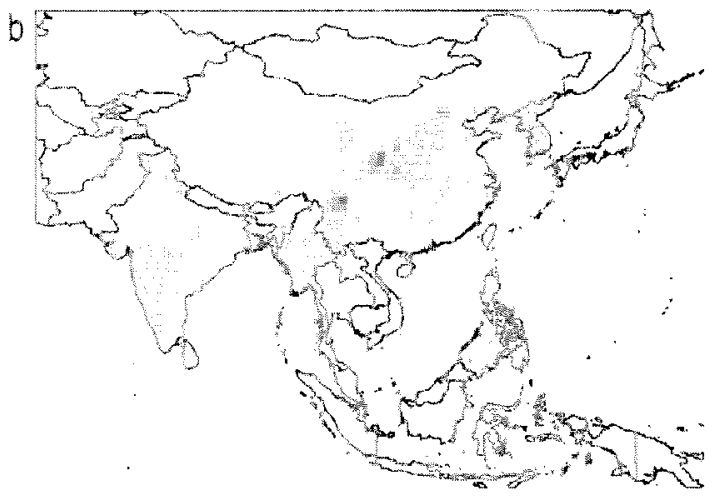

BC (ABBI) 1-10 March 2001

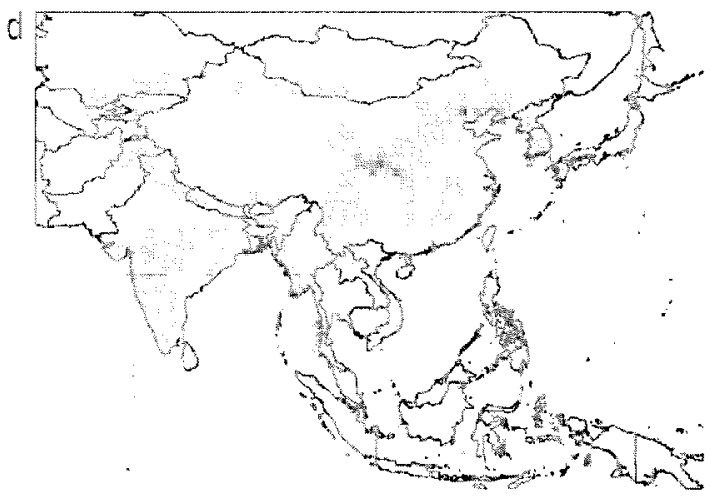

BC (ABBI) 11-20 March 2001

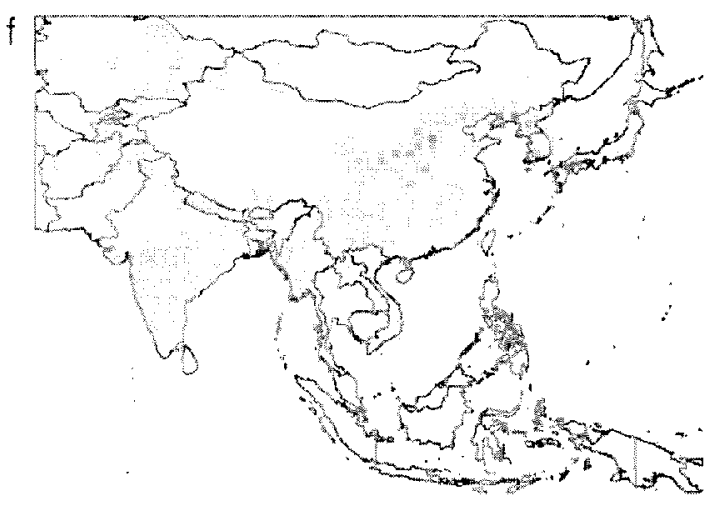

$\mathrm{BC}$ (ABBI) 21-31 March 2001

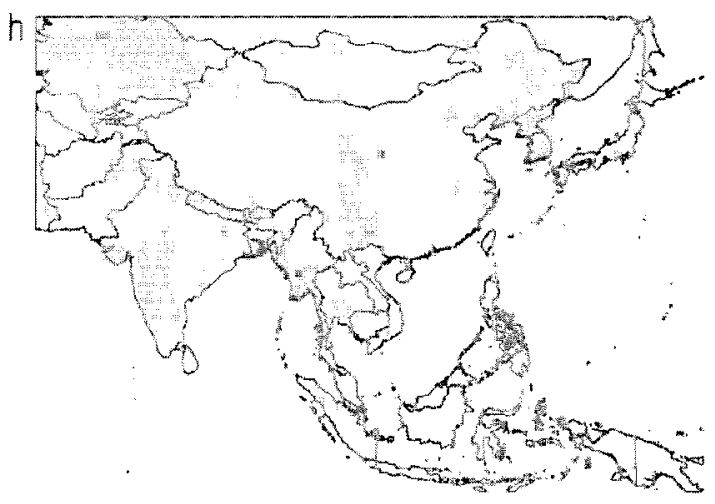

BC (ABBI) 1-10 April 2001

Figure 2 


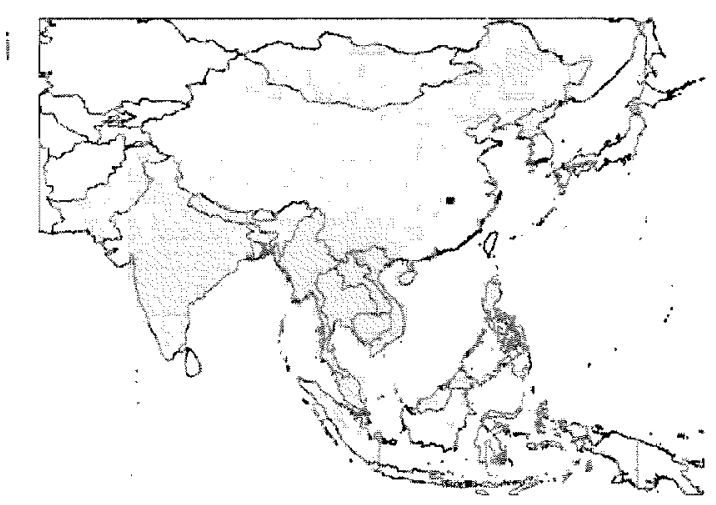

BC (ACESS) 11-20 April 2001

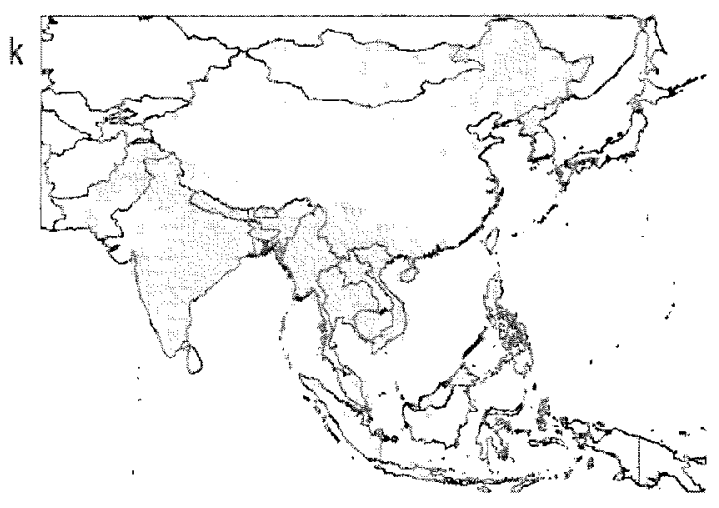

BC (ACESS) 21-30 April 2001

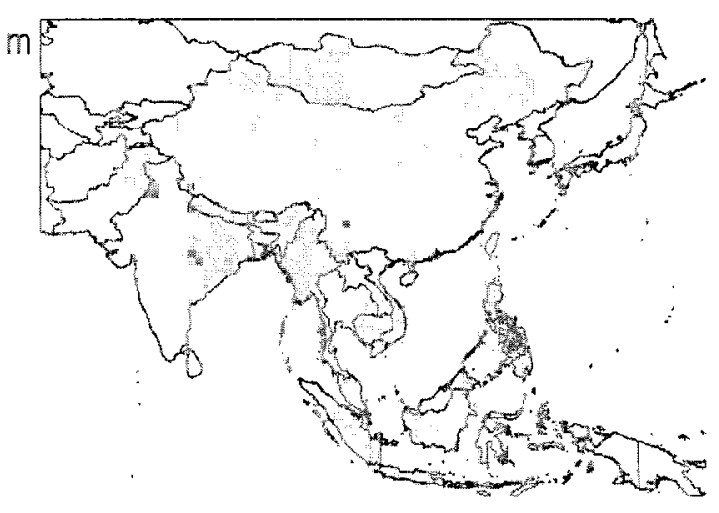

BC (ACESS) 1-10 May 2001

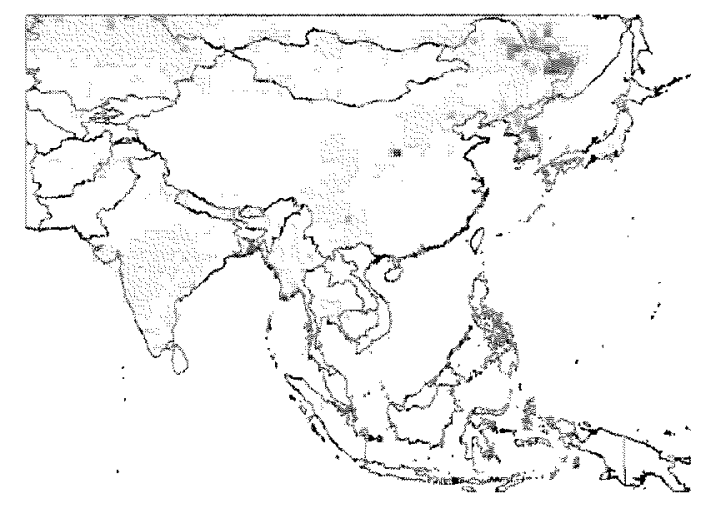

BC (ABBI) 11-20 April 2001

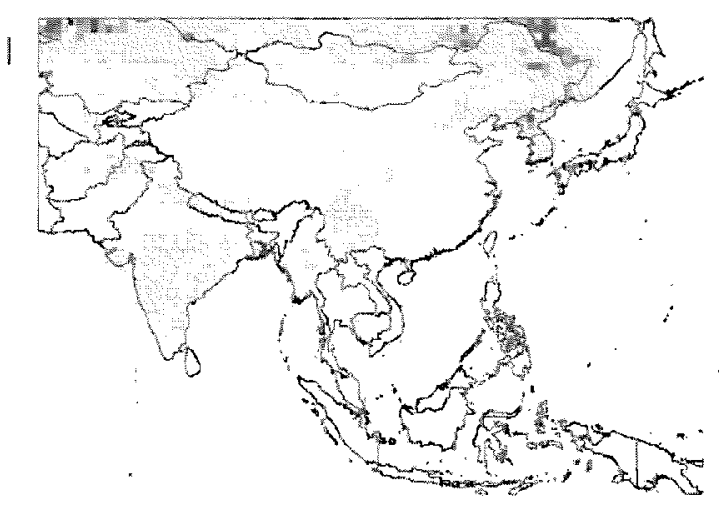

BC (ABBI) 21-30 April 2001

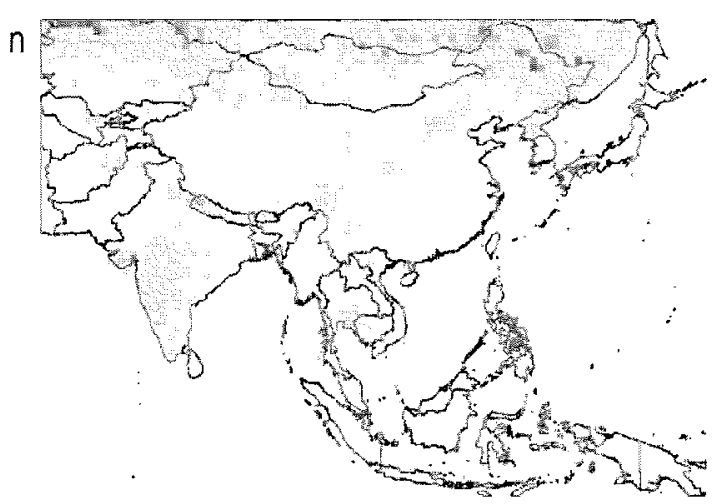

BC (ABBI) 1-10 May 2001

- BC emissions (tonnes/pixels)

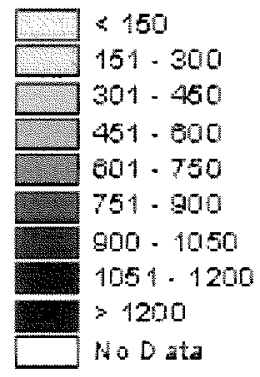

Figure 2. (continued) 


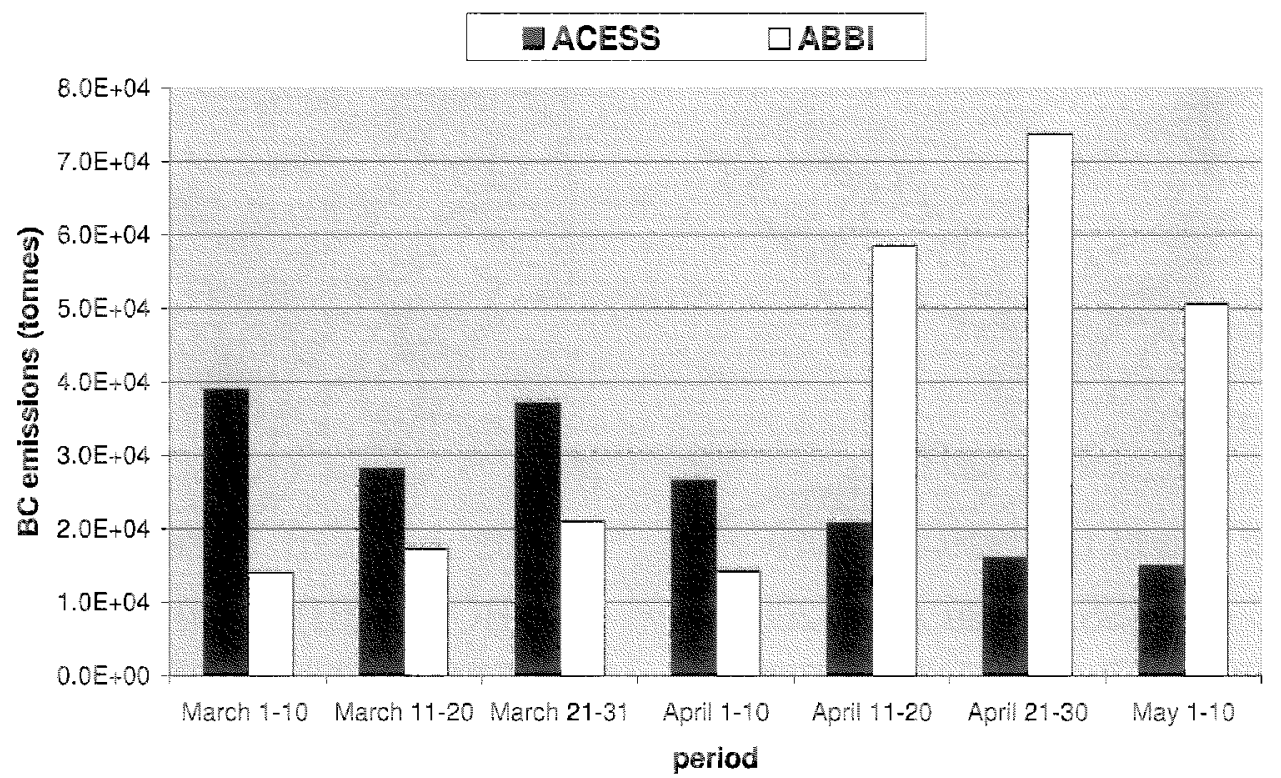

Figure 3. A comparison of the temporal distribution of black carbon (BC) emissions in the ACESS and ABBI inventories over 10 day periods (the daily emissions are summed) in 2001.

[31] A systematic correlation between the two inventories was not performed as it is highly dependant of the type and condition of the vegetation and season. An improved emission estimate may be obtained using a multisystem approach, which would take advantage of all the global fire products made available by the remote sensing community. Specifically one could use the following.

[32] 1. The hot spot products in the dense tropical forest, as derived from the NOAA-AVHRR and Tropical Rainfall Measuring Mission-Visible and Infrared Scanner (TRMM-VIRS) systems (both day time), and from the European Remote Sensing Satellite-Along Track Scanning Radiometer (ERS-ATSR system (nighttime).

[33] 2. The burnt area products in all the other types of vegetation cover, as derived from the SPOT-VEGETATION (GBA2000), ERS-ATSR (GLOBSCAR) and TERRA/ AQUA MODIS systems. This is the subject for future study.

\subsection{Intercomparison of ABBI Inventory for 2000 and 2001}

[34] The interannual variability of emissions estimated using ABBI was explored for two years (i.e., 2000 and 2001). We first focus on the type and distribution of the burnt biomass during the ACE-Asia and TRACE-P campaigns in 2001, then on $C O$ and $B C$ emissions. A comparison with the year 2000 is also presented, which has been processed using the same method as 2001 .

\subsubsection{Description of the Burnt Biomass}

[35] Figure 4 shows the temporal distribution of bumt areas in March, April and the first half of May 2001. Vegetation fires are low at the beginning before growing in number until the end of the campaign. The maximum fire amount is in April and early May, which seems to signify the end of fire activity in this region, and is probably caused by the onset of the monsoon rains that occur in late May. This is especially true in the southern part of the study area. The results for 2000 have been added in Figure 4. We see that the total estimate of burnt area in 2000 is slightly lower than in 2001 (except in May) with $189,238 \mathrm{~km}^{2}$ compared to $213,626 \mathrm{~km}^{2}$. Overall, the temporal distribution of burning activity is similar. Figure 5 shows that the main vegetation types burnt during the observation period (at 15 day intervals) is cropland, which represents $27 \%$ of the total burnt area. Grassland, woodland and wooded grassland also burn in considerable amounts when compared to the forest and shrub land families. A similar repartition (not presented here) is observed in the year 2000; except for the 1 to 15 May period where grassiand and cropland were less affected ( $\sim 50 \%$ less) by biomass burning than in 2001 . For the same period, but contrary to the previous example, burning activity in deciduous broadleaf forest is doubled for the year 2000 . For evergreen broadleaf forest, estimates for the year 2000 were $140 \mathrm{~km}^{2}$, but almost zero (only $2 \mathrm{~km}^{2}$ bumt) for 2001 .

[36] Figure 6 shows the distribution of burnt areas for five periods of 15 days along 14 latitudinal strips, five degrees wide in 2001. In March, the vegetation fires are located between $15^{\circ} \mathrm{N}$ and $45^{\circ} \mathrm{N}$ as at latitudes greater than $45^{\circ} \mathrm{N}$ there is still snow cover. However, a few days after the snow has melted, from the beginning of April onward, the northern region is affected by fires. Such latitudinal distribution is also observed in the year 2000 .

[37] The amount of burnt biomass is quite similar for the years 2000 and 2001, approximately 561 and $607 \mathrm{Tg}$ of dry matter, respectively. Furthermore, the temporal distribution of bumt biomass data is in general agreement with the distribution of burnt areas. Differences occur when we focus on biomass burning per vegetation type. A few of these differences are noted here, for example, for the second half of March, the amount of burnt biomass is lower in 2001 (52.61 Ty of dry matter) than in 2000 (55.07 Tg of dry matter), whereas the burnt areas is seen to be higher in 2001 than in 2000 . The same pattern is observed for the second half of April and in early May, again the 


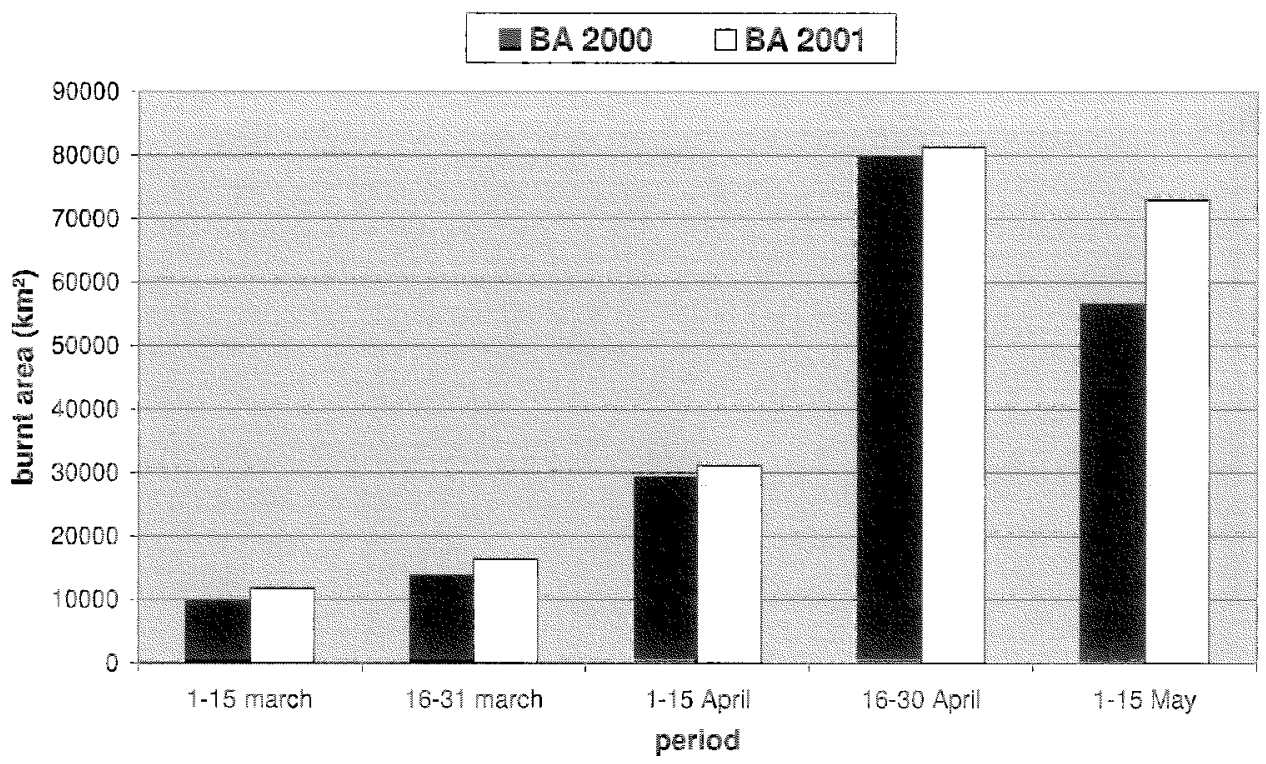

Figure 4. A comparison of the temporal distribution of burnt areas between the years 2000 and 2001 over 15 days periods (the daily data are summed).

difference between 2000 and 2001 is lower in terms of burnt biomass than in terms of burnt areas. It appears that buming of forests, characterized by high biomass density coefficients, causes these differences. This confirms the sensitivity of vegetation parameterization (choice of biomass density and burning efficiency) in the calculation of the emissions and also the need for accurate land cover maps.

3.2.2. Distribution of Biomass Burning Emissions

[38] Differences between emissions in 2000 and 2001 are not very significant in terms of total amount of gases or particles. However important differences arise conceming

\section{1-15 March 16-31 March $\square$ 1-15 April 16 16-30 April 1-15 May}

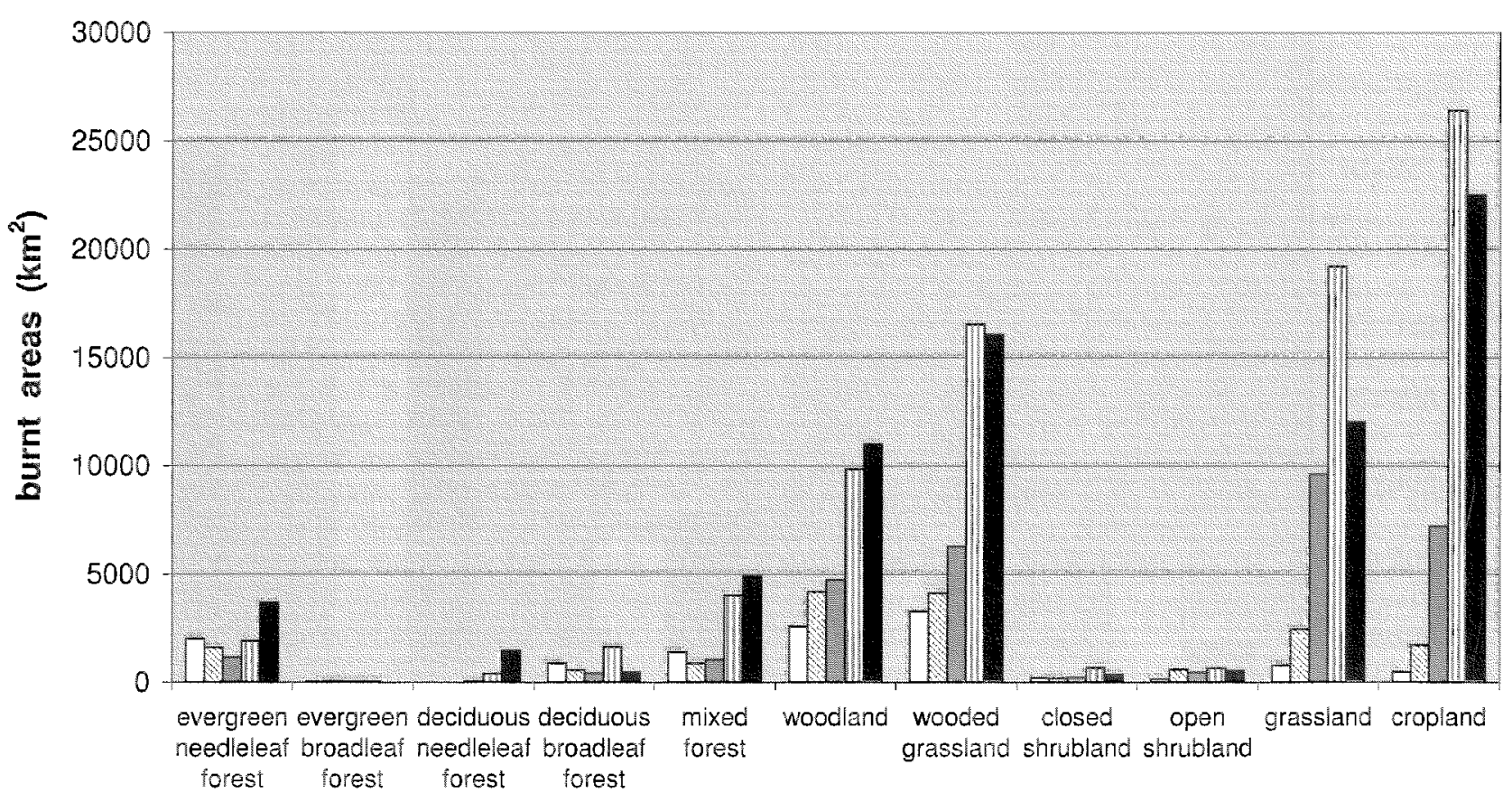

vegetation type

Figure 5. The distribution of burnt areas per vegetation type in March, April, and May 2001 (the daily data are summed over 15 day periods). 


\section{W 1-15 March $16-31$ March $\square$ 1-15 April $\square$ 16-30 April $=1-15$ May}

\section{latitudinal strips}

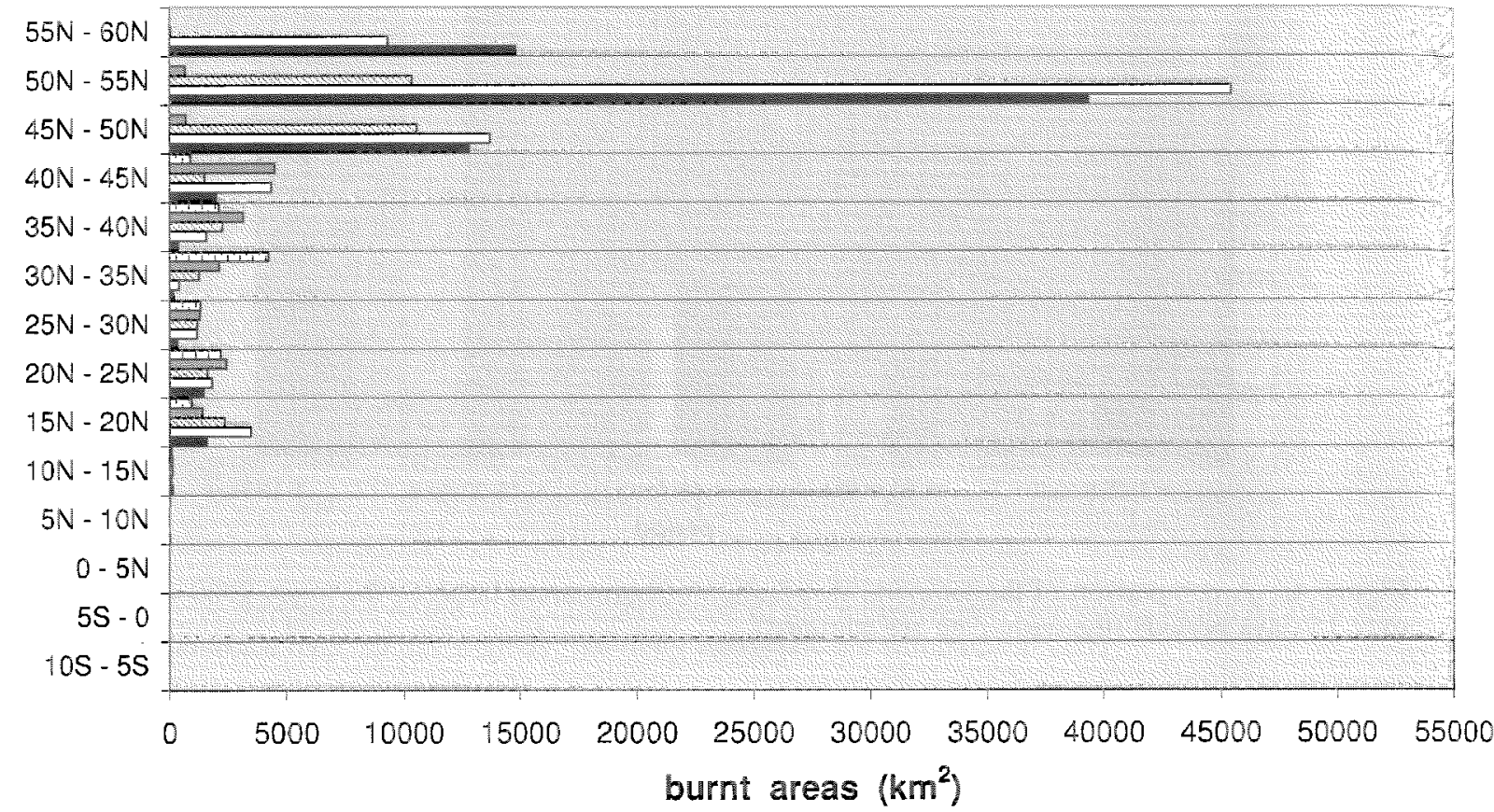

Figure 6. The latitudinal distribution (covering 14 strips, each of $5^{\circ}$ ) computed over 15 day periods in March and April and up to 15 May 2001.

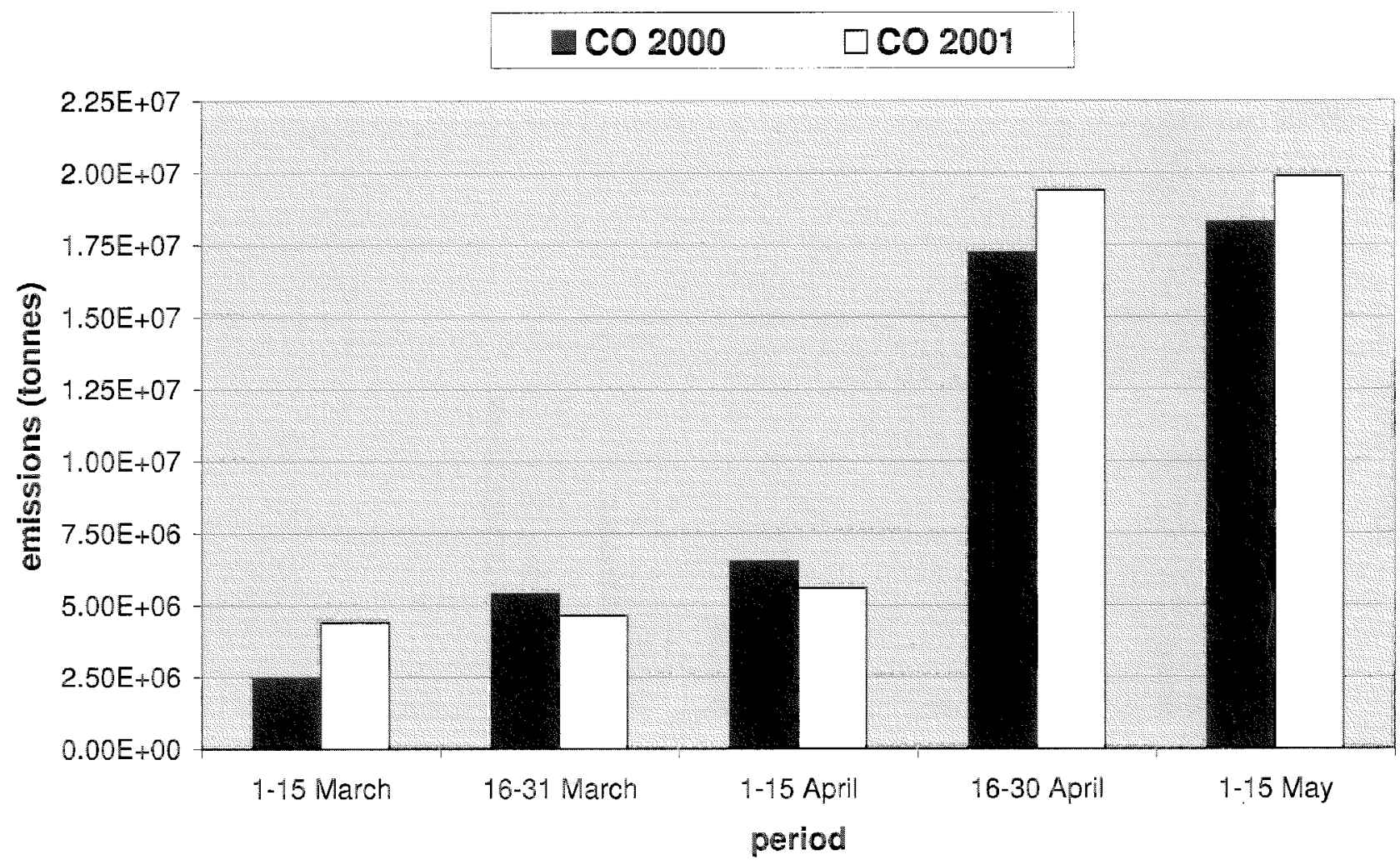

Figure 7. A comparison of the distribution of $\mathrm{CO}$ emissions between 2000 and 2001 over 15 day periods (the daily emissions summed for 15 days period). 


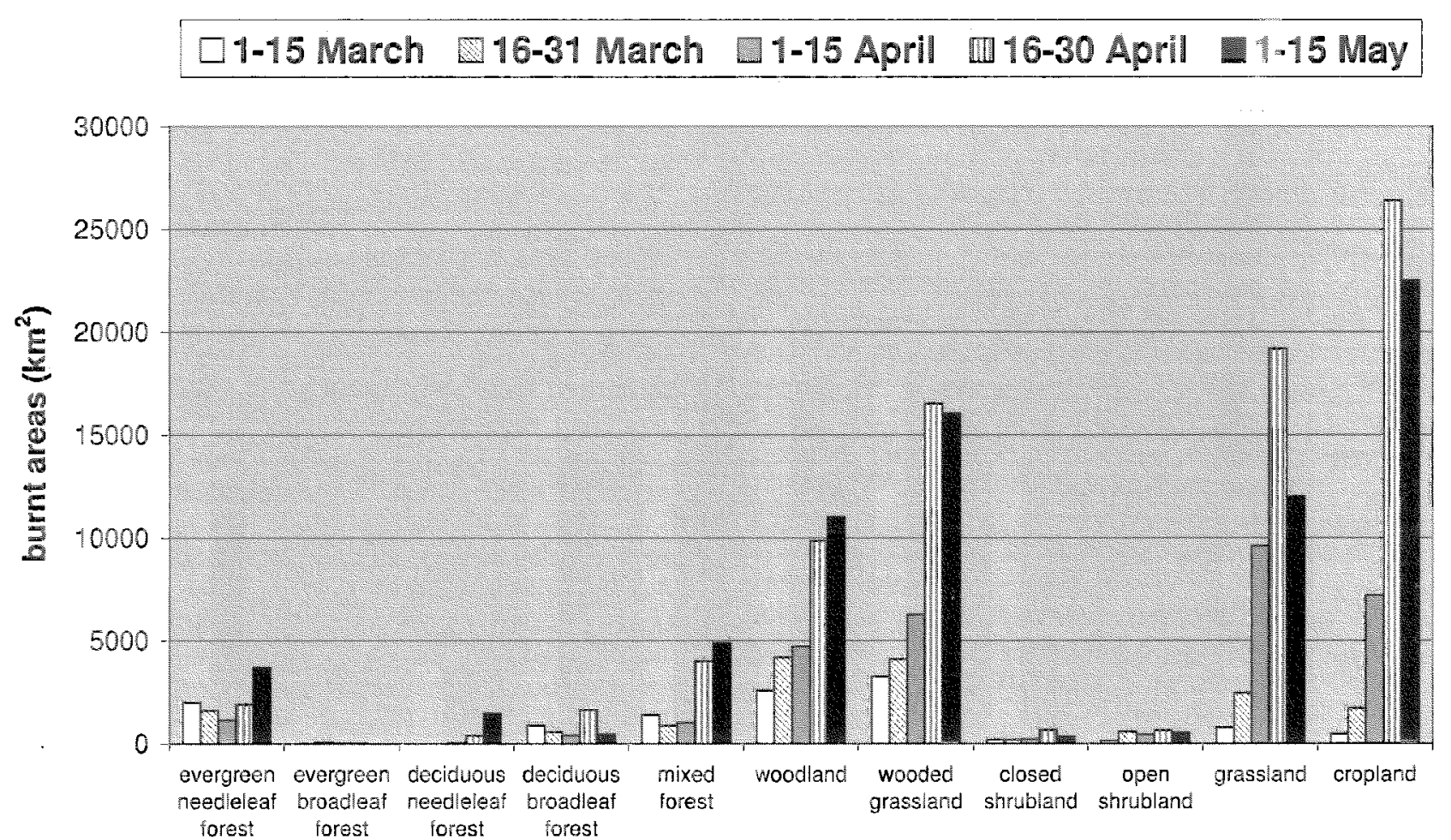

vegetation type

Figure 8. A comparison of the temporal distributions of black carbon (BC) emissions in China, India, and Kazakhstan over 15 days period (the daily emissions are summed) between the years 2000 and 2001 .

the spatial and temporal distributions. Figure 7 shows the distribution and amount of CO emissions for the year 2001 during the months of March, April, and May. Values for 2000 have been added for comparison. For the whole studied period, the $\mathrm{CO}$ emissions are of the same order for the both years: $4.99 \mathrm{E}+7$ and $5.39 \mathrm{E}+7 \mathrm{t}$ of $\mathrm{CO}$ emitted in 2000 and 2001 , respectively.

\subsubsection{Temporal Discributions}

[39] The temporal distribution of emissions (on the basis of 15 day comparisons) is in agreement with the bumt area and the burnt biomass temporal distributions. However, due to differences between the bumt vegetation types; more $\mathrm{CO}$ emissions are predicted in 2000 than in 2001 for the second period of March: $5.40 \mathrm{E}+6 \mathrm{t}$ (2000) compared to $4.64 \mathrm{E}+$ $6 t(2001)$ and for the first period of April: $6.52 \mathrm{E}+6 \mathrm{t}$ (2000) compared to $5.61 \mathrm{E}+6 \mathrm{t}(2001)$.

\subsubsection{Spatial Distribution}

[40] At the beginning of the ACE-Asia and TRACE-P period (March 2001), emissions are located in India, Southeast Asia, south and east of China. As previously seen with the burnt area distributions, from the end of March and during April, the emissions grow in the northem part of the window in Kazakhstan, southem Russia, Mongolia, and northern China, though being still present in the Southeast Asia. This evolution is the same for both years. Nevertheless, some shifts in space and time may be noticed with important differences in the intensity of the emissions. Figure 8 shows the temporal distribution of $\mathrm{BC}$ emissions over China, India, and Kazakhstan in 2000 and 2001. During the first period of March over India and China, $\mathrm{BC}$ emissions in 2000 are less than half the value of 2001 , whereas, during the second period of March, an opposite tendency is noticed in China. At the end of the studied period, a difference, amounting to a factor of 100 , of the $\mathrm{BC}$ emissions appears between the two years over Kazakhstan $(2.38 \mathrm{E}+3 \mathrm{t}$ of $\mathrm{BC}$ in 2000 compared to $2.12 \mathrm{E}+4 \mathrm{t}$ in 2001). The area over Thailand shows that there were no emission during the first period in 2001 , whereas 903 if of $\mathrm{BC}$ was emitted in 2000 . This amount is important as during the other months emissions never exceeded $100 \mathrm{t}$ of $\mathrm{BC}$.

3.2.3. Discussion

[41] The main differences encountered when comparing the evolution of burnt areas, burnt biomass and $\mathrm{BC}$ and $\mathrm{CO}$ emissions, between 2000 and 2001 are found in their temporal and spatial distributions, which can be explained by variations in the type of vegetation burnt. Figure 9 shows for each vegetation class, the burnt area versus the total vegetated area for 2000 and 2001 . It can be seen that the land cover classified as grasslands, comprising grassland, open and closed shrub land, woodland, wooded grassland, are always higher in 2001 than in 2000 , except for the woodland class. For the forest classes, burning in both the evergreen forest and the deciduous needleleat forest is more significant in 2000 than in 2001 . If we now focus on the repartition in terms of percentage of the burnt areas per country and per vegetation type, large differences appear between both years. For example, $45 \%$ of the total forest fires are situated in Russia in 2000 , compared to $38 \%$ in 2001 , and with China contributing $38 \%$ in 2000 compared to $44 \%$ in 2001 . For grassland fires, the highest difference occurs in Mongolia (10\% in 2000 and 2\% in 2001) and in Kazakhstan (16\% in 2000 and $23 \%$ in 200 ). India contrib- 


\section{burnt areas/vegetation areas (2000) $\square$ burnt areas/vegetation areas (2001)}

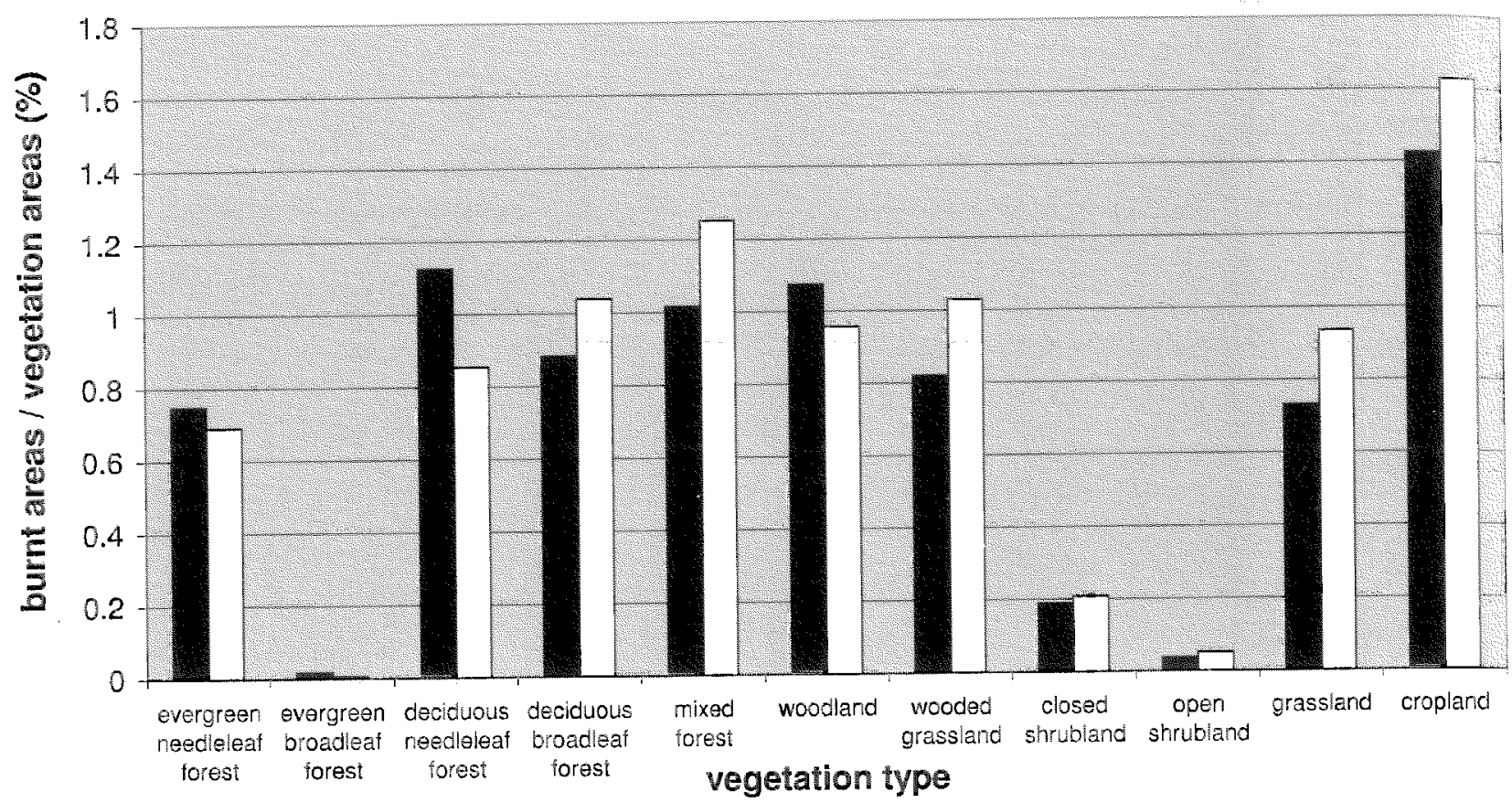

Figure 9. A comparison of the total burnt vegetation versus total vegetated area for the years 2000 and 2001

wed $10 \%$ in 2000 and $15 \%$ in 2001 . It is interesting to note that in this context, $\mathrm{BC}$ emissions in China are always lower in 2000 compared to 2001 , whatever the vegetation type. The figures show that $43 \mathrm{Gg}$ of $\mathrm{BC}$ were emitted in 2000 compared to $52 \mathrm{Gg}$ in 2001 from grassland buming, 32 and $35 \mathrm{Gg}$ of $\mathrm{BC}$ from forest buming and 18 and $23 \mathrm{Gg}$ of $\mathrm{BC}$ from cropland burning in 2000 and 2001 respectively. Similar patterns are observed in South Korea, the total amount of $\mathrm{BC}$ emitted during $\mathrm{ACE}-\mathrm{Asia}$ is $39 \mathrm{Gg}$ and $51 \mathrm{Gg}$ and in North Korea, $63 \mathrm{Gg}$ and $103 \mathrm{Gg}$ in 2000 and 2001 respectively. We note a systematic difference between China, North Korea and South Korea for 2000 and 2001.

[42] Finally, even though the global emission estimates are of the same order of magnitude for 2000 and 2001, a high variability of the spatial and temporal distribution have been shown, which confirms the need of using date specific of bum area information data to build cmission inventories.

\section{Conclusion}

[43] Biomass burning emission inventories derived from satellite burnt area data (called $A B B 1$ ) provide a methodology to quantitatively improve the global biomass burning emission estimates. In this paper we apply this technique to the estimate of biomass burning emissions over Asia. Our results show that Asian biomass burning contributes significantly to the injection of gases and aerosols into the atmosphere. Indeed, values of the BC emissions from Asian fossil fuel consumption and biomass buming during the studied period, are found to be of the same order: $5.57 \mathrm{E}+5 \mathrm{t}$ of fossil fuel $\mathrm{BC}$ [Liousse et al., 1996] compared to approximately $3.90 \mathrm{E}+5 \mathrm{t}$ of biomass burning $\mathrm{BC}$. The use of satellite derived bumt area provides avallable information on both the location of fres as well as biomass burnt. However uncertainties still remain, including knowledge of the true fraction of a one $\mathrm{km}^{2}$ pixel actually bumt. Investigations are ongoing to better improve this knowledge using a multi satellite approach [Boschetti et al., 2004a, 2004b, 2004c; J.-M. Gregoire, EU Joint Research Centre, personal communication, 2003]. Further improvements require better emission factors and vegetation factors, as already mentioned by Kasischke and Penner [2004]. As shown in this paper, differences in burnt area alone do not imply a proportional change in emission estimates. In fact, total BC emissions over Asia from 1 March to 15 May 2001 are quite different depending on the choice of emission factors. From our value of $\mathrm{EF}(\mathrm{BC}), 3.90 \mathrm{E}+5$ t of $\mathrm{BC}$ aro estimated, compared to $4.77 \mathrm{E}+5$ t of $\mathrm{BC}$ with the $\mathrm{EF}(\mathrm{BC})$ estimate of Liousse et al. [1996], and to $3.49 \mathrm{E}+5 \mathrm{t}$ of $\mathrm{BC}$ with the $\mathrm{EF}(\mathrm{BC})$ from Andreae and Merlet [2001].

[44] A comparison of Asian biomass burning emissions for the same period and area, derived from two different methods, one based on a climatic year of burnt biomass based on ground surveys and corrected by fire pixel distribution (ACESS), and our inventory based on the burn area mapping (ABBI), shows regional estimates of the same order (1.11E $+5 \mathrm{t}$ of $\mathrm{BC}$ for $\mathrm{ABB}$ (values excluding $\mathrm{FSU}$ and Kazakhstan contribution) and $1.83 \mathrm{E}+5 \mathrm{t}$ of $\mathrm{BC}$ for ACESS). However, significant spatial and temporal differences were observed. The comparisons of $\mathrm{ABB}$ I inventory for 2000 and 2001 have pointed out important interannual variability, especially in terms of the spatial and temporal distribution of bumt areas, burnt biomass and emissions. This variation is slightly different for the three parameters, which are highly dependent on the burnt vegetation type 
and competitive effects between the variation of the biomass density and the emission factors.

[45] This analysis has also shown that despite all the uncertainties described in this paper, the method selected in our study is the most convenient for episode specific analysis in Asia.

[46] Finally, the results from this study have identified three major recommendations for further improvements.

[47] 1. The correlation between the two products burnt area and hot spot products depends strongly on the type and condition of the vegetation and time of year which makes it difficult to derive quantitative bumt area products from hot spot data. A multisystem approach that incluoes both hot spot and burnt area products, should provide better information on when it bums, where it burns and what burns.

[40] 2. Owing to the importance of vegetation type, a future study necds to combine the bumt area products with the recent Global Land Cover 2000 (GLC2000) product [Bartholomé and Belward, 2005], which has provided an improvement from existing land cover products derived from low resolution satellite data (IGBP-DIS and UMD). A comparison of emission inventories could be made for each of these land cover products.

[49] 3. Finally, the key method used in this paper to derive emissions, is highly linked to the availability of burnt area products. An encouraging development for our research community is the preparation of the Global Land Products for Carbon Model Assimilation (GLOBCARBON) project from the European Space Agency (ESA) based on methods developed by the GBA2000 project and covering the period 1998 to 2003.

\section{References}

Akeredolu, F., and A. O. Isichei (1991), Emissions of carbon, nitrogent, and sulfur from biomass burning in Nigeria, in Global Biomass Burning: Atmospheric Climatic, and Biospherie Implications, edited by 3 . S. Levine, pp. 162-166, MIT Press, Cambridge, Mass.

Andreae, M. O., and P. Merlet (2001), Enissions of trace gases and aerosols from bionass burning, Global Biogeochem. Cycies, 15(4), 955-966.

Barbosa, P. M., D. Stroppiana, J-M. Gregolre, and J. M. C. Percira (1999), An assessment or̂ vegetation fire in Africa (1981-1991): Eurned areas, buned biomass, and amospheric emissions, Global Blogeochem Cycles, 13, 933-950.

Bartholomé, E., and A. S. Belward (2005), GLC2000: A new approach to global land cover mapping from Eath observation data, Int. J. Remote Sens., in press.

Belward, A. S., J.-M. Grégoire, G. D'Souza, S. Trigg, M. Hawkes, J.-M Brustet, D. Serça, J.-L. Tireford, J.-M. Charlot, and R. Vuatrotix (1993) ln-situ real-time fre cietection using NOAA-AVIRR data, in procedings of the 6th AVHRR Data Users Meeting, Betgirate, Haly, July 1993 , EUMETSAT Rep. EUM P 12, pp. 333-339, Eur: Org. for the Exploit. of Meteorol. Satelites, Darmstadt Gernany.

Bilbao, E., and E. Medina (1996), Types of grassland fires and nimogen volatilization in tropica Savannas of Calabozo, Venezucla, in Biomass Buming and Global Change, edited by I. S. Levine, pp. 569-574, MT Press, Cambridge, Mass.

Boschetti, L., H. Eva, P. A. Brivio, and J. Gallego (2004a), The validation protocol of GBA2000 global bumed area maps, paper preserted at IGARSS IEEE IntemationaI Geoscience and Remote Sensing, Land Degradation and Fires Session, Geophys. Inst., Univ. of Alaska Fairbanks, Anchorage, Alaska, 20-24 Sept.

Boschetti, L., H. Eva, P. A. Brivio, J. Gallego, and J.-M. Gregoite (2004b), Validation protocols for GBA2000, paper presented at CEOS Cal-Val Land Cover Vaidation Workshop, Comm. on Earth Observ. Sateliites, Boston Univ, Boston, Mass., 2-4 Feb.

Boschetti, L., H. D. Eva, P. A. Brivio, and J. M. Grégoire (2004c), Lessions to be learned from the comparison of three satcllite-derived bionas burning producs, Geophys. Res. Let., 31, L21501, doi:10.1029 2004 GLOL21229
Cooke, W. F., and J. J. N. Wilson (1996), A slobal bock carbon aerosol model, J. Geophys. Res., 101, 19,395-19,409.

Cooke, W. F., C. Liousse, and I. Cachier (1999), Constwetion of a $1^{\circ} \times 1^{\circ}$ fussi suel emission data set for carbonacentis aerosol and innlementation and radiative impact in the ECIAM4 model, f. Geophys. Res., 104, $137-162$

Crassies, V., K. Suhre, Tulet, and R. Rosset (2000), Development of a reduced chenical scheme for use in mesoscale reteorological models, Atmos. Environ. 34, $2633-2644$.

DeFries, R., M. Hansen, J. R. G. Townshend, and R. Sohberg (1998), Global land cover dassifications at $8 \mathrm{~km}$ soatid resolution: The sise of training data derived from Landsat magery in decision tree classîners, ht. S. Remole Sers. 10.3141-3168.

Dimon, J., and J. E. Penner (1991), Bionass buming: A source of nitrogen xides in the atmosphere, in Biomass Burving and Glohal Change, edited by 3. 5. Lovine, n. 370 375, MiT Press, Cambridge, Mass.

Eastwood, J. A., S. E. Pumme, B. K. Wyat, and B. J. Stocks (1998), The potential of SPOT-VEGETATION data for fre scare detection in boreal foresis, Int. J. Remote Sens., 19, 3681-3687.

Ershov, D. V., and V. P. Novik (2001), Features of burnt area mapping in forest of Sibcria using SPOT SI ..VEGETATION data paper presented at GOFC Fite Satelite Product Valdation Workshe, Gubenkian Found. Lisbon, 9 July.

Eva, H., and E. F. Lambin (1998), Burnt area mapping in Central Africa using ATSR data, Int. J. Remote Sens., I9(18), 3473-3497.

Fraser, R. H., and Z. Li (2002), Estimating Tre-related paraneters in boreal forest using SPOT-VEGETATION, Remote Sens. Environ., 82, $95-110$.

Gregoire, J.-M. K. Tansey, and J. M. N. Silva (2003), The GBA2000 initative: Developing a global buned area database from SPOT-VEGETATION imagery, hit. J. Renote Sens. 24(6), 1369-1376.

Hansen, M., R. DeFries, J. R. G. Townshend, and R. Sohberg (2000), Global hand cover classification at $1 \mathrm{~km}$ resolution using a decision tree classifier, Int. J. Remote Sens., 21, 1331-1365.

Hao, W. M. M. H. Liu, and Is. J. Crutzen (1990), Estimates of annual and regional releases of $\mathrm{CO} 2$ and other trace gases to the atmosphere from fires in the tropics, based on the FAO Statistics for the period $1975-$ 1980 in Fine in the Tropical Biota, Ecol. Stud., vol. 84, edited by I. C. Goldammer, pp. 440-462, Springer, New York.

Hobbs, P. V., J. S. Reid, J. A. Herring, J. D. Nance, R. E. Weiss, J. L. Ross, D. A. Hegg, R. D. Ottmar, and C. Lloussc (1996), Particle and trace gas measurements in the smoke from preseribed burns of forest products in the Pacilic Northwest, in Biomass Burning and Global Change, elited by J. S. Levine, pp. 697-715, MIT Press, Cambricige, Mass.

Hoelzeman, J. 3., M. G. Schultz, G. P. Brasseu, C. Granier, and M. Simon (2004), Gobal Wildand Fire Emission Model (GWDM): Evaluating the usc of global area burnt satellite data, .J. Geophys. Res., 109, D14804, doi: $10.1029 / 2003.5003666$.

Hoffa, E. A., D. E. Ward, W. M. Hat, R. A. Susott, and R. H. Wakimoto (1996), Seasonality if carbon emissions from bicmass buming in a Zambian savanna, $J$ Geophys Res. /1)4(D)1) 13,841 13,853 .

Huchen, B. J., T. Bates, P. B. Russel, G. Shi, Y. J. Kim, K. Kawamura, (5. Carmichael, and T. Nakajma (2003), An overview of ACL-Asia Sirategies for quantifying the relationships berween Asian aerosols and their climatic impacis, $J$. Geophws. Res., I08(D23), 8633, doi:10.1029/ 2003110003550.

Hurst, D. F., D. W. T. Grifth, and G. D. Cook (1994), Trace gas emissions from biomass buming in tropical Australian savannas, $J$. Geophys. Res., $99(08), 16,441-16,456$.

Kasischke, E. S., and J. E. Penner (2004), Inproving global estimates of atmospheric emissions from biomass butning, $I$. Geophys. Res., 10\%, D 14501 , do: $10.1029 / 2004.10004972$

Kasischke, E. S., B. J. Stocks, K. O'Neill, N. H. F. French, and L. L. Bourgeau-Chavez (2000), Direct effect of fire on the boreal forest carbon budget, in Biomass Burning and Its Inter-Relationships With the Clinat System, edited by J. L. Intres, M. Beniston, and M. M. Verstraet, pp. 617). Dordrecht, Norwell, Misss.

Levine, J. S. (2000), Global biomass burning: A case study of the gaseous and particulate enissions released to the atmosphere durng the 1997 fires in Kalimantan and Sumatra, Tndonesia, in Biomass Buming and Its InterRelationshios With the Climate System, edited by I. L. Mnes, M. Beniston, and M. M. Verstrate, pp. 15-31, Dordrecht, Norwell, Mass.

Liousse, C., J. E. Penner, C. Chuang, J. J. Walton, H. Eddieman, and H. Cachier (1996), A global three-dimensional model study of carbonaceous acrosols, J. Geophys. Res, 101. 19,411-19,432

Liousse, C., et al. (2004), Deriving global quantitative estimates for spatial and temporal distributions of biomass buring emissions, in Emissions of Atmospheric Trace Compotnds, edited by $C$ Ganier, $P$. Artaxo, and C. Reeves, pp. 71-113, Donưnech, Nowwil, Mass. 
Middleton, P., IV. R. Stockwell, and WV. P. L. Carter (1990), Aggregation and analysis of volatile organic compound emissions for regional modelling, Atmos. Emiron. Part A, 24, 1107-1133.

Olivier, J. G. J., and J. J. M. Berdowski (2001), Global emission sources and sinks, in The Climate System, edited by J. Berdowski, R. Guicherit, and B. J. Heij, pp. 33-78, A. A. Balkema, Brookfield, Vt.

Olson, J. S., J. A. Watts, and L. J. Allisson (1985), Major world ecosystem complexes ranked by carbon in live vegetation: A database NPD017, Oak Ridge Lab., Oak Ridge, Tenn

Palacios, A., E. Chuvieco, and C. Carmona-Moreno (2002), FUEGO II Project: Development of Global Firc Analysis GIS Modules-Trace Gas Emission Estimation in Biomass Burning, Rep. EUR 20376 EN: 41, Eur. Comm., Luxembourg.

Scholes, R. J., D. E. Ward, and C. O. Justice (1996), Emissions of trace gases and aerosol particles due to vegetation burning in southem hemisphere Africa, J. Geophys. Res., 101, 23,677-23,682.

Seiler, W., and P. J. Crutzen (1980), Estimates of gross and net fluxes of carbon between the biosphere and the atmosphere from biomass burning, Clim. Change, 2, 207-248.

Stockwell, IV. R., P. Middleton, J. S. Chang, and X. Tang (1990), The second generation regional acid deposition model chemical mechanism for regional air quality modelling, $J$. Geophys. Res., 95, 16,343-16,367.

Stockwell, W. R., F. Kirchner, M. Kuhn, and S. Seefeld (1997), A new mechanism for regional atmospheric chemistry modelling, $J$. Geophys. Res., 102, 25,847-25,879.

Streets, D. G., K. F. Yarber, J.-H. Woo, and G. R. Carmichael (2003), Biomass buming in Asia: Annual and seasonal cstimates and atmospheric emissions, Global Biogeochem. Cycles, 17(4), 1099, doi:10.1029/ 2003GB002040.

Susott, R. D., D. E. Ward, R. E. Babitt, and D. J. Latham (1991), The measurement of trace emissions and combustion characteristics for mass fire, in Global Biomass Burning: Almospheric, Climatic and
Biospheric Implications, edited by J. S. Levine, Pp. 245-257, MIT Press, Cambridge, Mass.

Tansey, K. (2002), Implementation of regional burnt area algorithms for the GBA2000 initiative, Rep. EUR 20532, 159 pp., Eur. Comm., Luxembourg. Tansey, K., et al. (2004), Vegetation burning in the year 2000: Global bumed area cstimates from SPOT VEGETATION data, J. Geophys. Res., 109, D14S03, doi:10.1029/2003JD003598.

Tansey, K., et al. (2005), A global inventory of bumed areas at $1 \mathrm{~km}$ resolu. tion for the year 2000 derived from SPOT VEGETATION data, Clim Change, 67(2), 345-377.

Trigg, S., and S. Flasse (2000), Characterizing the spectral-temporal response of burned savannah using in situ spectroradiometric and infrared thermometry, Int. J. Remote Sens., 21, 3161-3168.

Van der Werf, G. R., J. T. Randerson, G. J. Collatz, and L. Giglio (2003) Carbon emissions from fires in tropical and subtropical ecosystems, Global Change Biol., 9(4), 547-562.

Woo, J., et al. (2003), Contribution of biomass and biofuel emissions to trace gas distributions in Asia during the TRACE-P experiment, J. Geophys. Res., IOS(D21), 8812, doi:10.1029/2002JD003200.

G. R. Carmichael and J.-H. Woo, Center for Global and Regional Environmental Research, University of Iowa, lowa City, IA 52242, USA

J.-M. Grégoire, European Commission's Joint Research Center, Institute for Environment and Sustainability, TP 440, I-21020 Ispra (VA), Italy.

C. Liousse and C. Michel, Laboratoire d'Aćrologie, OMP, UMR 5560 CNRS-UPS, 14 Avenue E. Belin, F-31400 Toulousc, France. (micc@ acro.obs-mip.fr)

K. Tansey, Department of Geography, University of Leicester, University Road, Leicester LEI 7RH, UK. 